\title{
ELECTRODYNAMICS OF PLASMA-FILLED CORRUGATED COAXIAL STRUCTURE
}

\author{
I.N.Onischenko, D.Yu.Sidorenko, G.V.Sotnikov \\ Institute of Plasma Electronics and New Methods of Acceleration National Science Center \\ “Kharkov Institute of Physics and Technology", 61108, Kharkov, Ukraine, Akademicheskaya \\ st. 1 \\ E-mail:onish@kipt.kharkov.ua
}

\begin{abstract}
The interaction of electronic beam with plasma-filled coaxial waveguide with corrugated external radius is investigated. The dispersion equation, which describes interaction of beam with such slowing down structure, is obtained. The properties of eigen waves of structure depending on plasma density are investigated numerically. It is shown that for non-relativistic electronic beams maximal growth rate of instability for plasma-filled slowing down structure considerably exceeds the one for vacuum structure. The non-linear estimations of waves excitation efficiency in such system are carried out.
\end{abstract}

\section{Introduction}

The vacuum slowing down structures (SDS), which are used in Cherenkov microwave generators and amplifiers, accelerators of charged particles, have an essential shortcoming due to surface character of the slow wave. The decreasing of longitudinal field component from periphery to system axis causes the fall of coefficient of coupling of near-axis beam with a slow wave, and this results in reduction of instability growth rates in generators or acceleration rate in accelerators. This shortcoming is especially strong in the high frequency range. In the other class of SDS - in homogeneous plasma waveguides [1] - the slowed down waves are volumetric and have the maximal longitudinal electrical field at the axis, where charged particles use to move. However in non-relativistic region of phase velocities the plasma waves are quasi-longitudinal, with small transversal components of fields, that complicates microwave energy input and output. Hybrid systems, which are perspective in non-relativistic region of speeds, were offered for the first time in KIPT. They combine in themselves the advantages of vacuum and plasma systems and have no shortcomings marked above. The hybrid structure uses plasma waveguide as the beam transition channel of vacuum SDS [2,3]. In such structure beam-plasma interaction plays the determining role in excitation of oscillations, and periodic waveguide system is used for output of power. The important advantage of coaxial systems is the presence of a cable mode with a wide frequency band, including low-frequency range. It is essential for microwave devices, which work in a continuous stochastic spectra generation mode, or in multifrequency mode.

\section{The dispersion equation}

The axially symmetric waveguide, formed by two coaxial ideally conducting cylinders is considered (Fig.1). The internal cylinder is smooth, external one is corrugated sinusoidally with a period $D$. In the cylindrical system of coordinates $(r, \varphi, z)$ waveguide surfaces are given as:

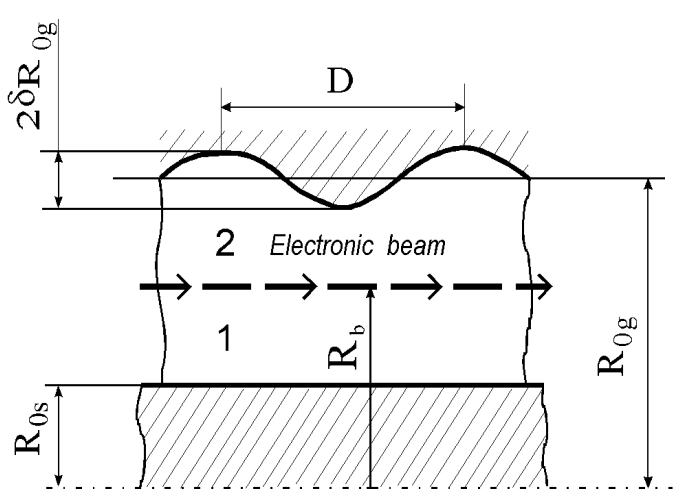

Fig. 1 Geometry of system.

$\mathrm{R}_{\mathrm{s}}(\mathrm{z})=\mathrm{R}_{0 \mathrm{~s}}=$ const , $\quad \mathrm{R}_{\mathrm{g}}(\mathrm{z})=\mathrm{R}_{0 \mathrm{~g}}\left(1+\delta \cdot \cos \left(\mathrm{k}_{0} \mathrm{z}\right)\right)$, $\mathrm{k}_{0}=2 \pi / \mathrm{D}$, where $\mathrm{R}_{0 \mathrm{~s}}<\mathrm{R}_{0 \mathrm{~g}}(1-\delta),-\infty<\mathrm{z}<\infty$, $0 \leq \varphi \leq 2 \pi, 0<\delta<<1$. It is supposed, that waveguide is filled with homogeneous plasma and is placed in a strong magnetic field $\omega_{c}>\omega_{p}$, where $\omega_{c}$ is the cyclotron frequency and $\omega_{p}$ is the electron plasma frequency. Waves of E-type $\left(\mathrm{E}_{\mathrm{z}}, \mathrm{E}_{\mathrm{r}}, \mathrm{H}_{\varphi}\right)$ are considered. We solve the Maxwell equations system together with boundary conditions for tangential component of electrical field on a surface of waveguide and we find the dispersion of electromagnetic waves $\omega\left(\mathrm{k}_{3}\right)$ proceeding from a condition of existence of the non-trivial solution of this system, as it was made in [4].

\subsection{The dispersion equation of plasma-filled coaxial waveguide.}

As the corrugated waveguide is periodical along Zaxis, components of electromagnetic field, according to the Floquet theorem, can be presented as a series of spatial harmonics: $F\left(\vec{r}_{\perp}, z\right)=\sum_{n=-\infty}^{\infty} A_{n} f_{n}\left(\vec{r}_{\perp}\right) e^{i k_{\mid} \mathrm{n}^{z}}$, where $\mathrm{k}_{|| \mathrm{n}}=\mathrm{k}_{3}+\mathrm{k}_{0} \mathrm{n}, \mathrm{k}_{3}$ is the longitudinal wave number. For axially symmetric E-wave fields in the region between internal and external cylinders are:

ВОПРОСЫ АТОМНОЙ НАУКИ И ТЕХНИКИ 2000. №1.

Серия: Плазменная электроника и новые методы ускорения (2), с. 17-21. 
$E_{z}(r, z, t)=\sum_{n=-\infty}^{\infty} E_{z n}=\sum_{n=-\infty}^{\infty} A_{n} F_{0}\left(k_{\perp n} r\right) \exp (z, t)$,

$\mathrm{E}_{\mathrm{r}}(\mathrm{r}, \mathrm{z}, \mathrm{t})=\sum_{\mathrm{n}=-\infty}^{\infty} \mathrm{E}_{\mathrm{rn}}=\sum_{\mathrm{n}=-\infty}^{\infty} \frac{-\mathrm{i} \varepsilon_{||} \mathrm{k}_{|| \mathrm{n}}}{\mathrm{k}_{\perp \mathrm{n}}} \mathrm{A}_{\mathrm{n}} \mathrm{F}_{1}\left(\mathrm{k}_{\perp \mathrm{n}} \mathrm{r}\right) \exp (\mathrm{z}, \mathrm{t})$,

$\mathrm{H}_{\varphi}(\mathrm{r}, \mathrm{z}, \mathrm{t})=\sum_{\mathrm{n}=-\infty}^{\infty} \mathrm{H}_{\varphi \mathrm{n}}=\sum_{\mathrm{n}=-\infty}^{\infty} \frac{-\mathrm{i} \varepsilon_{\mid} \mid \omega / \mathrm{c}}{\mathrm{k}_{\perp \mathrm{n}}} \mathrm{A}_{\mathrm{n}} \mathrm{F}_{1}\left(\mathrm{k}_{\perp \mathrm{n}} \mathrm{r}\right) \exp (\mathrm{z}, \mathrm{t})$,

where $\exp (\mathrm{z}, \mathrm{t}) \equiv \mathrm{e}^{\mathrm{i}\left(\mathrm{k}_{\mid \ln } \mathrm{z}-\omega \mathrm{t}\right)}, \quad \mathrm{k}_{\perp \mathrm{n}}^{2} \equiv \varepsilon_{||}\left(\omega^{2} / \mathrm{c}^{2}-\mathrm{k}_{\mid \mathrm{n}}^{2}\right)$, $\varepsilon_{||}=1-\omega_{\mathrm{p}}^{2} / \omega^{2}, \quad \omega_{\mathrm{p}}^{2}=4 \pi \mathrm{n}_{\mathrm{p}} \mathrm{e}^{2} / \mathrm{m}_{\mathrm{e}} \quad$ is the electronic plasma frequency, $n_{p}$ is the plasma density, $-e$ and $\mathrm{m}_{\mathrm{e}}$ are the charge and mass of electron accordingly, $\mathrm{F}_{0}\left(\mathrm{k}_{\perp \mathrm{n}} \mathrm{r}\right)=\mathrm{N}_{0}\left(\mathrm{k}_{\perp \mathrm{n}} \mathrm{R}_{0 \mathrm{~s}}\right) \mathrm{J}_{0}\left(\mathrm{k}_{\perp \mathrm{n}} \mathrm{r}\right)-\mathrm{J}_{0}\left(\mathrm{k}_{\perp \mathrm{n}} \mathrm{R}_{0 \mathrm{~s}}\right) \mathrm{N}_{0}\left(\mathrm{k}_{\perp \mathrm{n}} \mathrm{r}\right)$,

$\mathrm{F}_{1}\left(\mathrm{k}_{\perp \mathrm{n}} \mathrm{r}\right)=\mathrm{N}_{0}\left(\mathrm{k}_{\perp \mathrm{n}} \mathrm{R}_{0 \mathrm{~s}}\right) \mathrm{J}_{1}\left(\mathrm{k}_{\perp \mathrm{n}} \mathrm{r}\right)-\mathrm{J}_{0}\left(\mathrm{k}_{\perp \mathrm{n}} \mathrm{R}_{0 \mathrm{~s}}\right) \mathrm{N}_{1}\left(\mathrm{k}_{\perp \mathrm{n}} \mathrm{r}\right) ;$ $\mathrm{J}_{0}, \mathrm{~J}_{1}, \mathrm{~N}_{0}, \mathrm{~N}_{1}$ are cylindrical Bessel and Nejmann functions.

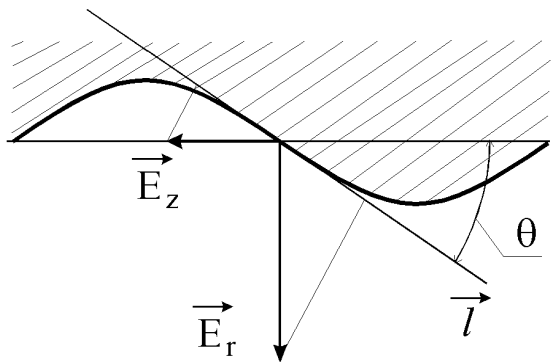

Fig.2 To the boundary conditions at the corrugated surface of waveguide.

The boundary condition on corrugated surface of waveguide can be written in components of electrical field $E_{z}$ and $E_{r}$ (Fig.2) in the following form:

$$
\mathrm{E}_{\mathrm{z}}\left(\mathrm{R}_{\mathrm{g}}(\mathrm{z})\right)+\mathrm{E}_{\mathrm{r}}\left(\mathrm{R}_{\mathrm{g}}(\mathrm{z})\right) \cdot \operatorname{tg}(\theta(\mathrm{z}))=0 \text {, }
$$

where $\operatorname{tg} \theta=d R_{\mathrm{g}} / d z=-\delta \mathrm{k}_{0} \mathrm{R}_{0 \mathrm{~g}} \sin \left(\mathrm{k}_{0} \mathrm{z}\right)$. Substituting fields (1) into (2) after appropriate transformations we received the following infinite system of algebraic equations for $A_{n}$ :

$$
\begin{gathered}
\sum_{\mathrm{n}=-\infty}^{\infty} \mathrm{A}_{\mathrm{n}} \mathrm{C}_{\mathrm{mn}}\left(\omega, \mathrm{k}_{3}\right)=0,-\infty<\mathrm{m}<\infty, \\
\mathrm{C}_{\mathrm{mn}}\left(\omega, \mathrm{k}_{3}\right)=\frac{1}{\mathrm{D}} \int_{-\mathrm{D} / 2}^{\mathrm{D} / 2} \mathrm{~F}_{0}\left[\mathrm{f}_{\mathrm{n}}(\mathrm{z})\right] \mathrm{e}^{\mathrm{i} \mathrm{k}_{0}(\mathrm{n}-\mathrm{m}) \mathrm{z}} \mathrm{dz} \times \\
\times\left[1+\frac{\varepsilon_{|| \mathrm{k}_{\mid} \mid \mathrm{n}} \mathrm{k}_{0}(\mathrm{n}-\mathrm{m})}{\mathrm{k}_{\perp \mathrm{n}}^{2}}\right]
\end{gathered}
$$

where $\mathrm{f}_{\mathrm{n}}(\mathrm{z}) \equiv \mathrm{k}_{\perp \mathrm{n}} \mathrm{R}_{0 \mathrm{~g}}\left(1+\delta \cdot \cos \left(\mathrm{k}_{0} \mathrm{z}\right)\right)$. The system (3) can have the non-trivial solution, only if its determinant is equal to zero. This defines the required dispersion equation:

$$
\operatorname{det}\left\|\mathrm{C}_{\mathrm{mn}}\right\|=0 \text {. }
$$

\subsection{The dispersion equation for structure with a} beam.

Let the axially symmetric tubular infinitely thin monoenergetic electronic beam propagates along the system axis. Beam density $\mathrm{n}_{\mathrm{b}}(\mathrm{r})=\left[\mathrm{I} / 2 \pi \mathrm{ev}_{\mathrm{b}} \mathrm{R}_{\mathrm{b}}\right] \delta\left(\mathrm{r}-\mathrm{R}_{\mathrm{b}}\right)$, where $v_{b}, I, R_{b}$ are velocity of particles, current and radius of beam accordingly. We consider fields in two regions (Fig.1): 1 - between an internal cylinder surface and beam, 2 - between beam and external corrugated cylinder surface. The boundary conditions on beam for fields $\mathrm{E}_{\mathrm{z}}$ and $\mathrm{E}_{\mathrm{r}}$ are:

$$
\begin{aligned}
& {\left[\mathrm{rE}_{\mathrm{r}}\right]=\frac{2 \mathrm{iek}_{3} \mathrm{IE}_{\mathrm{z}}}{\mathrm{m}_{\mathrm{e}} \mathrm{v}_{\mathrm{b}} \gamma_{\mathrm{b}}^{3}\left(\omega-\mathrm{k}_{3} \mathrm{v}_{\mathrm{b}}\right)^{2}},} \\
& {\left[\mathrm{E}_{\mathrm{z}}\right]=0,}
\end{aligned}
$$

where $[\mathrm{f}] \equiv \mathrm{f}\left(\mathrm{R}_{\mathrm{b}}+0\right)-\mathrm{f}\left(\mathrm{R}_{\mathrm{b}}-0\right), \gamma_{\mathrm{b}}$ is the relativistic factor of beam. In the region 1 field can be presented in the form (1). In the region 2 we have:

$$
\begin{aligned}
& E_{z}^{2}(r, z, t)=\sum_{n=-\infty}^{\infty} A_{n}\left[x_{n} J_{0}\left(k_{\perp n} r\right)+y_{n} N_{0}\left(k_{\perp n} r\right)\right] \exp (z, t), \\
& E_{r}^{2}(r, z, t)=\sum_{n=-\infty}^{\infty} A_{n} \frac{-i \varepsilon_{\mid}\left|k_{\mid}\right| n}{k_{\perp n}}\left[x_{n} J_{1}\left(k_{\perp n} r\right)+y_{n} N_{1}\left(k_{\perp n} r\right)\right] \times \\
& \times \exp (z, t) .
\end{aligned}
$$

We matched fields from regions 1 and 2 on boundary $\mathrm{r}=\mathrm{R}_{\mathrm{b}}$ taking into account boundary conditions (6) and satisfying boundary conditions (2) on corrugated waveguide surface. Similarly to the case with no beam we received the dispersion equation in form (5) with only difference, that instead of $\mathrm{F}_{0}\left[\mathrm{f}_{\mathrm{n}}(\mathrm{z})\right]$ in (4) was:

$$
\begin{aligned}
& \mathrm{T}_{0}\left(\mathrm{z}, \mathrm{k}_{3}, \omega, \mathrm{n}\right) \equiv \mathrm{G}_{0}\left(\mathrm{k}_{\perp \mathrm{n}}, \mathrm{R}_{0 \mathrm{~s}}, \mathrm{R}_{\mathrm{g}}(\mathrm{z})\right)- \\
& -\frac{2 \mathrm{ek}_{\perp \mathrm{n}} \mathrm{IG}_{0}\left(\mathrm{k}_{\perp \mathrm{n}}, \mathrm{R}_{0 \mathrm{~s}}, \mathrm{R}_{\mathrm{b}}\right)}{\mathrm{m}_{\mathrm{e}} \mathrm{v}_{\mathrm{b}} \gamma_{\mathrm{b}}^{3} \mathrm{R}_{\mathrm{b}} \varepsilon_{||}\left(\omega-\mathrm{k}_{|| \mathrm{n}} \mathrm{v}_{\mathrm{b}}\right)^{2}} \frac{\mathrm{G}_{0}\left(\mathrm{k}_{\perp \mathrm{n}}, \mathrm{R}_{\mathrm{b}}, \mathrm{R}_{\mathrm{g}}(\mathrm{z})\right),}{\mathrm{G}_{1}\left(\mathrm{k}_{\perp \mathrm{n}}, \mathrm{R}_{\mathrm{b}}, \mathrm{R}_{\mathrm{b}}\right)},
\end{aligned}
$$

where $\quad \mathrm{G}_{\mathrm{i}}\left(\mathrm{k}_{\perp \mathrm{n}}, \mathrm{R}_{1}, \mathrm{R}_{2}\right) \equiv \mathrm{N}_{0}\left(\mathrm{k}_{\perp \mathrm{n}} \mathrm{R}_{1}\right) \mathrm{J}_{\mathrm{i}}\left(\mathrm{k}_{\perp \mathrm{n}} \mathrm{R}_{2}\right)_{-}$ $\mathrm{J}_{0}\left(\mathrm{k}_{\perp \mathrm{n}} \mathrm{R}_{1}\right) \mathrm{N}_{\mathrm{i}}\left(\mathrm{k}_{\perp \mathrm{n}} \mathrm{R}_{2}\right)$.

It is easy to notice that when $\mathrm{I} \rightarrow 0$ function $\mathrm{T}_{0}\left(\mathrm{z}, \mathrm{k}_{3}, \omega, \mathrm{n}\right)$ turns into function $F_{0}\left[f_{n}(z)\right]$. The choice of a thin beam allowed us to "extract" beam component from arguments of cylindrical functions, where it would enter in case of beam with final thickness [4]. This eliminates set of beam harmonics appearing in case of beam with final thickness when $\omega \rightarrow \mathrm{k}_{|| \mathrm{n}} \mathrm{v}_{\mathrm{b}}$, and simplifies the analysis of results.

\section{Results of the numerical analysis of the dispersion equation}

\subsection{Dispersion of plasma-filled waveguide.}

For the numerical solution of equation (5) the following parameters of system were chosen: $\mathrm{D}=10 \mathrm{~cm}$, $\mathrm{R}_{0 \mathrm{~s}}=2 \mathrm{~cm}, \mathrm{R}_{0 \mathrm{~g}}=4 \mathrm{~cm}, \delta=0,1$. The dispersion picture for vacuum waveguide $\left(n_{p}=0\right)$ is presented on Fig. 3 . In case of the smooth external cylinder $(\delta=0)$ in such waveguide there are two types of waves: cable waves with dispersion $\omega=\mathrm{k}_{3} \mathrm{c}$ and fast electromagnetic waves $\omega^{2} / \mathrm{c}^{2}-\mathrm{k}_{3}^{2}=\mu_{\mathrm{n}}\left(\mathrm{R}_{0 \mathrm{~s}}, \mathrm{R}_{0 \mathrm{~g}}\right)=$ const . 


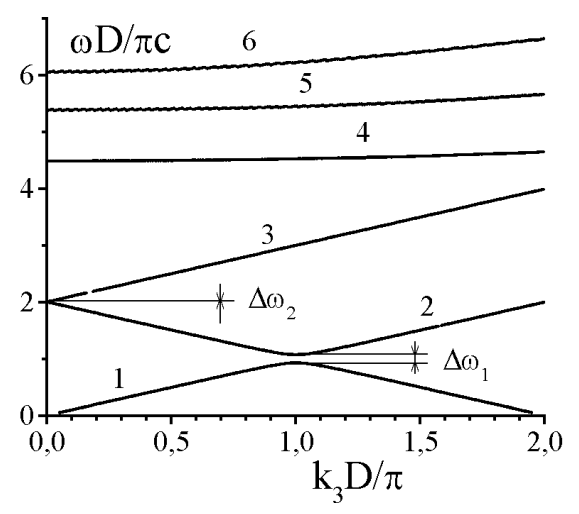

Fig. 3 Dispersion curves for vacuum structure. Curves 1,2, 3 - cable modes, curves 4,5,6 - fast EM - modes, which appeared due to Floquet-harmonics interaction.

Opacity bands $\Delta \omega_{1}$ and $\Delta \omega_{2}$ are represented schematically.
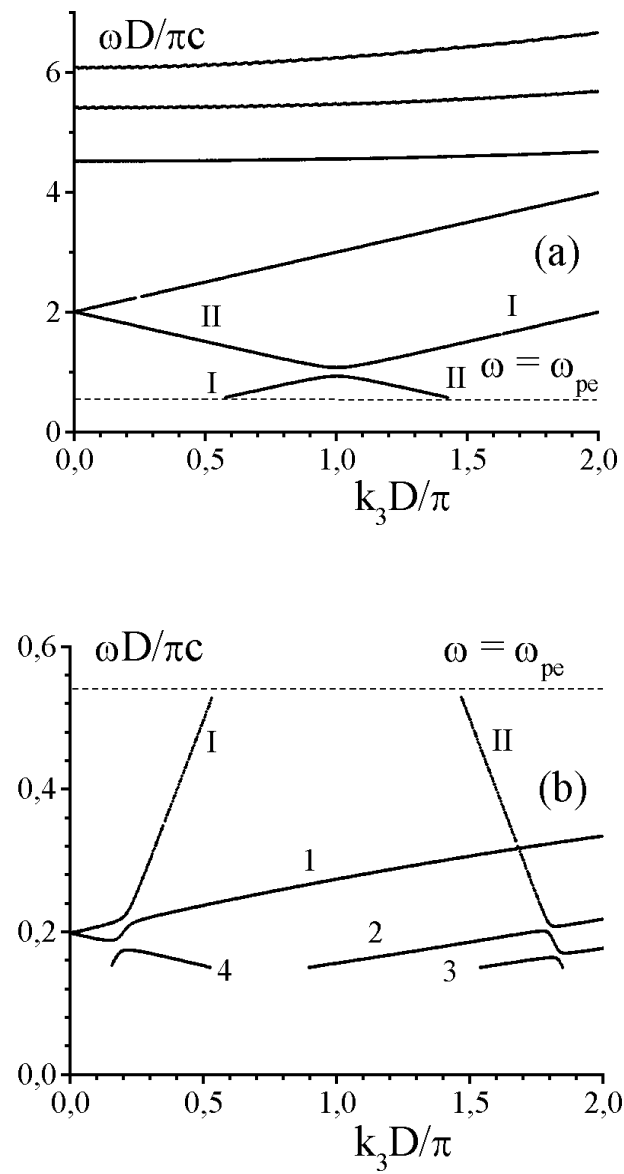

Fig. 4 Dispersion picture for the structure, filled with plasma $n_{p}=8 \cdot 10^{9} \mathrm{~cm}^{-3}$. Curve I-Floquet-harmonic of cable mode $n=0$, curve II - Floquet-harmonic of cable mode $n=-1$, curves 1-4 - radial plasma brunches,

corresponding to various Floquet-harmonics.

Corrugation results in appearance of Floquetharmonics and splitting of dispersion curves near the points of crossing of different Floquet-harmonics. Specifically, due to the interaction of harmonics 0 and 1, instead of wave $\omega=\mathrm{k}_{3} \mathrm{c}$ we receive (for $0<\mathrm{k}_{3} \mathrm{D} / \pi<1$ ) a wave with phase velocity, which is less than speed of light (curve 1). With growth of $\delta$ width of first opacity band $\Delta \omega_{1}(\omega \approx \pi c / D)$ increases linearly, and width of second opacity band $\Delta \omega_{2}(\omega \approx 2 \pi \mathrm{c} / \mathrm{D})$ by square-law.

On Fig.4 the dispersion picture is presented for waveguide, filled with plasma with density $\mathrm{n}_{\mathrm{p}}=8 \cdot 10^{9} \mathrm{~cm}^{-3}$, that corresponds to dimensionless plasma frequency $\omega_{\mathrm{p}} \mathrm{D} / \pi \mathrm{c}=0,535$. For $\omega>\omega_{\mathrm{p}}$ the dispersion does not differ qualitatively from a vacuum case. In this area the presence of plasma results only in some increasing of own waves frequencies (Fig.4.a). In area $\omega<\omega_{\mathrm{p}}$, where there are many radial plasma harmonics appropriate to Floquet-harmonics with $n=-1$, 0,1 splitting picture is much more complex (Fig.4.b).

For $\mathrm{n}_{\mathrm{p}}=1,3 \cdot 10^{11} \mathrm{~cm}^{-3}$ the whole range of frequencies of cable wave up to the first opacity band is located in area $\omega<\omega_{p}$. For the cable wave change of frequency is small, but the dispersion brunch becomes strongly split because of interaction with infinite number of radial Floquet-harmonics of plasma waves, forming the so-called dense spectrum [5]. It is the case, when the own wave of vacuum structure is covered by plasma waves, which is necessary to use in hybrid SDS [6].
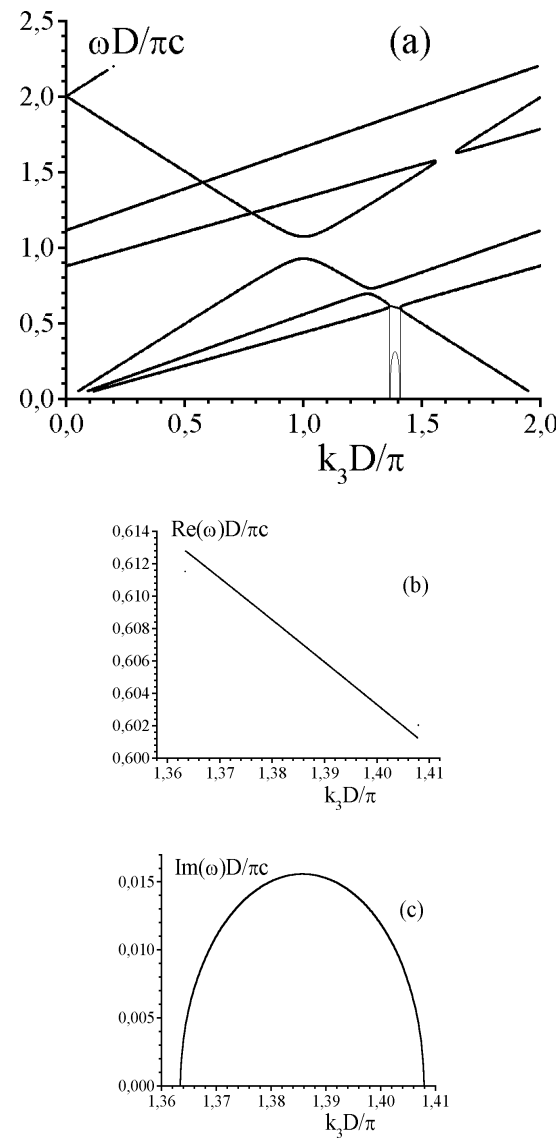

Fig. 5 Dispersion picture for vacuum structure with beam (a), instability region is represented schematically. Dependencies of frequency (b) and growth rate (c) of backward cable mode instability from longitudinal wavenumber. $\gamma_{b}=1,15, v_{b} / c=0,5$. 


\subsection{Interaction of beam with eigen waves of vacuum}

SDS.

The frequencies and growth rates of unstable oscillations which arise in beam-SDS system were received with $R_{b}=3 \mathrm{~cm}, I=200 A$. On Fig.5 the general dispersion picture and the dependencies of growth rate and frequency of unstable oscillations from $\mathrm{k}_{3}$ are presented for $\gamma_{\mathrm{b}}=1,15$. With growth of $\gamma_{\mathrm{b}}$ distance between fast and slow brunches of beam decreases and the beam velocity increases, that results in interaction with a direct cable mode.
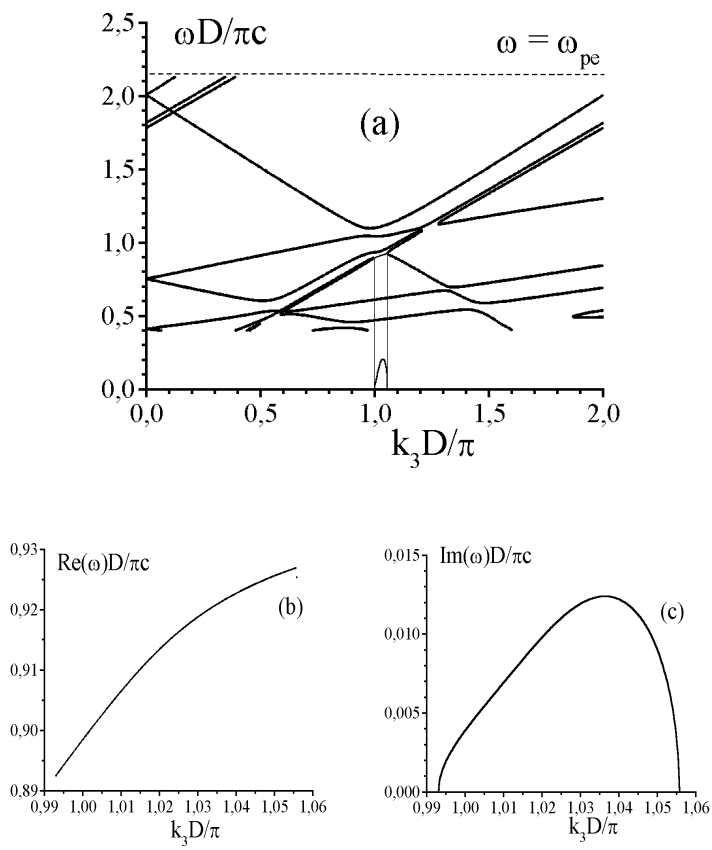

Fig.6 Dispersion picture (a) for structure, filled with plasma $n_{p}=1,3 \cdot 10^{11} \mathrm{~cm}^{-3}$, instability region is represented schematically. Dependencies of frequency

(b) and growth rate (c) of backward cable mode instability from longitudinal wavenumber.

$$
\gamma_{b}=2,29, v_{b} / c=0,9 \text {. }
$$

\subsection{Interaction of beam with eigen waves of plasma- filled SDS.}

As it was mentioned above, the presence of plasma in system results in appearing of set of additional branches of oscillations. The slow branches of beam Floquet-harmonics being crossed with them give the area of instability near the crossing point. Typical dispersion picture and the dependencies of growth rate and frequency of unstable oscillations from $\mathrm{k}_{3}$ for plasma case $\left(n_{p}=1,3 \cdot 10^{11} \mathrm{~cm}^{-3}, \gamma_{b}=2,29\right) \quad$ are presented on Fig.6. The instability near the point of crossing of slow brunch of zero beam harmonic with a cable mode has maximal growth rate, as well as in vacuum case.

On Fig.7 and Fig. 8 the dependencies of growth rates and frequencies of unstable oscillations from $\gamma_{b}$ for vacuum and also for plasma density $\mathrm{n}_{\mathrm{p} 1}=2,8 \cdot 10^{10} \mathrm{~cm}^{-3}$

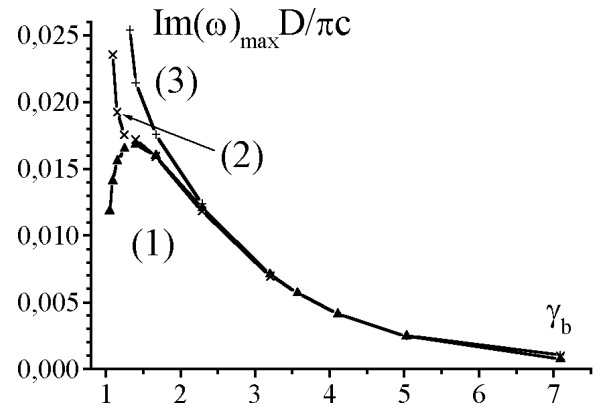

Fig. 7 Dependencies of cable mode instability growth rates from relativistic beam factor $\gamma_{b}$. Curve (1)-

$$
\begin{gathered}
\text { vacuum, (2) }-n_{p 1}=2,8 \cdot 10^{10} \mathrm{~cm}^{-3} \text {, (3) - } \\
n_{p 2}=1,3 \cdot 10^{11} \mathrm{~cm}^{-3} .
\end{gathered}
$$

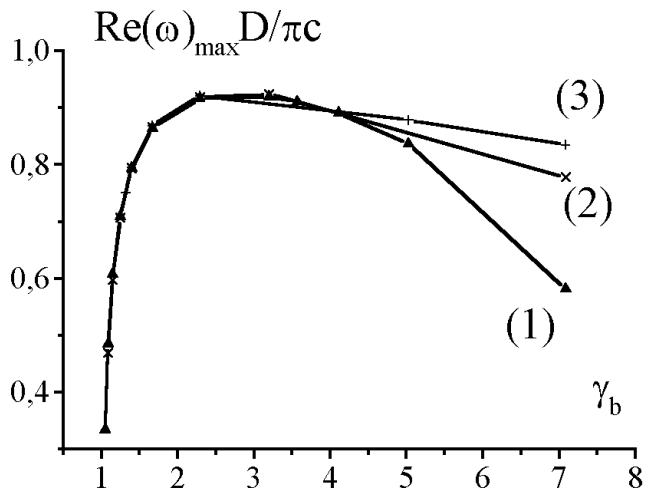

Fig. 8 Dependencies of cable mode instability frequency from relativistic beam factor $\gamma_{b}$. Curve (1) - vacuum,

$$
\text { (2) }-n_{p 1}=2,8 \cdot 10^{10} \mathrm{~cm}^{-3} \text {, (3) }-n_{p 2}=1,3 \cdot 10^{11} \mathrm{~cm}^{-3} \text {. }
$$

and $\mathrm{n}_{\mathrm{p} 2}=1,3 \cdot 10^{11} \mathrm{~cm}^{-3}$ are presented. For $\gamma_{\mathrm{b}}>2$ growth rates fall down with the increasing of $\gamma_{b}$ in all three cases practically equally. However at large $\gamma_{b}$ the frequency of instability grows with the increasing of plasma density rather considerably. With decreasing of $\gamma_{\mathrm{b}}$ for plasma $\mathrm{n}_{\mathrm{p} 1}$ growth rate almost coincides with vacuum one up to $\gamma_{\mathrm{b}} \approx 1,5$. But for smaller $\gamma_{\mathrm{b}}$ growth rate exceeds the vacuum one significantly. For more dense plasma $\mathrm{n}_{\mathrm{p} 2}$ growth rate begins to exceed vacuum growth rate already with $\gamma_{\mathrm{b}} \approx 2$. For smaller $\gamma_{\mathrm{b}}$ it exceeds the growth rate, appropriate to smaller plasma density $\mathrm{n}_{\mathrm{pl}}$. For $\gamma_{\mathrm{b}}<3$ the frequencies of unstable oscillations in all three cases with identical $\gamma_{\mathrm{b}}$ are very close one to one.

\section{Efficiency of excitation of electromagnetic waves}

The linear stage of interaction of electronic beam with a synchronous wave of corrugated coaxial line 
continues until non-linear processes of multi-mode interactions appear - decay, modulation instability etc. They redistribute microwave power of a raised synchronous wave across a spectrum and that stabilises level of raised microwave oscillations. The essential mechanism of stabilisation of instability of microwave oscillations build-up, which is coming before others, is the capture of beam in a field of the main synchronous wave (non-linearity "wave - particle") [7]. Growth rate of this wave was determined in the linear theory. In this case [7] the saturation takes place when growth rate $\operatorname{Im}(\omega)$ is comparable with frequency of trapped oscillations of beam particles in the wave field $\Omega$ :

$$
\operatorname{Im}(\omega) \approx \Omega,
$$

Where $\Omega=\sqrt{\mathrm{eE}_{\max _{\mathrm{z}}} \mathrm{k}_{3} /\left(\mathrm{m} \gamma_{\mathrm{b}}^{3}\right)}, \mathrm{E}_{\text {max }_{\mathrm{z}}}$ is the amplitude of saturation of longitudinal component of electrical field intensity. From here follows:

$$
\mathrm{E}_{\max _{\mathrm{z}}} \cong[\operatorname{Im}(\omega)]^{2} \mathrm{~m} \gamma_{\mathrm{b}}^{3} /\left(\mathrm{ek}_{3}\right) \text {. }
$$

The received expressions allow to estimate efficiency of excitation of microwave fields in considered structure. The efficiency of generation was defined as the ratio of a microwave power flow to a flow of electronic beam particles kinetic energy $S_{b}$ through the waveguide cross section. To calculate the microwave power flow the own waves of coaxial corrugated waveguide without beam were taken as:

$$
\begin{gathered}
\mathrm{E}_{\mathrm{z}}=\mathrm{E}_{\mathrm{zs}}=\mathrm{E}_{\mathrm{z}}^{0}=\mathrm{A}^{0} \cdot \mathrm{F}_{0}\left(\mathrm{k}_{\perp 0} \mathrm{r}\right) \cdot \exp (\mathrm{z}, \mathrm{t}), \\
\mathrm{H}_{\varphi}=-\mathrm{i} \varepsilon_{\mid} \mid \frac{\omega}{\mathrm{c}} \mathrm{A}^{0} \cdot\left[\frac{\mathrm{F}_{1}\left(\mathrm{k}_{\perp 0} \mathrm{r}\right)}{\mathrm{k}_{\perp 0}}-\frac{\mathrm{C}_{00}}{\mathrm{C}_{0-1}} \frac{\mathrm{F}_{1}\left(\mathrm{k}_{\perp-1} \mathrm{r}\right)}{\mathrm{k}_{\perp-1}} \mathrm{e}^{-i \mathrm{k}_{0} \mathrm{z}}\right] \exp (\mathrm{z}, \mathrm{t}),
\end{gathered}
$$

1)

i.e. it was supposed, that the basic contribution to a longitudinal electrical field gives harmonic with number 0 , and the power flow is determined by fields of harmonics with numbers 0 and -1 . As a result the following expression for efficiency was received:

$$
\begin{aligned}
& \eta=\frac{\mathrm{v}_{\text {гр }} \mathrm{m}}{\mathrm{D}} \frac{\gamma_{\mathrm{b}}^{6}{\omega^{2}}^{2} \varepsilon_{||}^{2}\left[\operatorname{lm}(\omega) \mathrm{k}_{3}^{2} \mathrm{c}^{4} \mathrm{~F}_{0}^{2}\left(\mathrm{k}_{\perp 0} \mathrm{R}_{\mathrm{b}}\right)\right.}{\gamma^{4}} \times \\
& \times \int_{0}^{\mathrm{D}} \mathrm{dz} \int_{\mathrm{R}_{0 \mathrm{~s}}}^{\mathrm{R}_{0 \mathrm{~g}}\left(1+\delta \cos \left(\mathrm{k}_{0} \mathrm{z}\right)\right)} \mathrm{dr} \cdot \mathrm{r}\left|\frac{\mathrm{F}_{1}\left(\mathrm{k}_{\perp 0} \mathrm{r}\right)}{\mathrm{k}_{\perp 0}}-\frac{\mathrm{C}_{00}}{\mathrm{C}_{0-1}} \frac{\mathrm{F}_{1}\left(\mathrm{k}_{\perp-1} \mathrm{r}\right)}{\mathrm{k}_{\perp-1}} \mathrm{e}^{-\mathrm{i} \mathrm{k}_{0} \mathrm{z}}\right|^{2}
\end{aligned}
$$

where $\mathrm{v}_{\text {гр }}$ is the group velocity of wave.

Results of investigations of influence of various parameters of electronic beam - SDS system on efficiency value are presented below. For calculation of $\omega, \mathrm{k}_{3}$ and $\operatorname{Im}(\omega)$ the dispersion equation, taking into account only harmonics with numbers 0 and -1 , was took. The beam current was equal to $400 \mathrm{~A}, \mathrm{D}=10 \mathrm{~cm}$, $\mathrm{R}_{0 \mathrm{~s}}=2 \mathrm{~cm}, \quad \mathrm{R}_{0 \mathrm{~g}}=4 \mathrm{~cm}, \quad \mathrm{R}_{\mathrm{b}}=3 \mathrm{~cm}, \quad \delta=0,1 . \quad$ The frequency $\omega$, appropriate to wave number $k_{3}$ of a maximum of growth rate of the instability $\operatorname{Im}(\omega)$ in case with no beam, was substituted into expression (12). The calculations were carried out for a case of vacuum structure and also for the following values of plasma density:

$$
\mathrm{n}_{\mathrm{p} 1}=1,3683 \cdot 10^{10} \mathrm{~cm}^{-3},
$$

$$
\mathrm{n}_{\mathrm{p} 2}=2,2619 \cdot 10^{10} \mathrm{~cm}^{-3}, \quad \mathrm{n}_{\mathrm{p} 3}=2,8 \cdot 10^{10} \mathrm{~cm}^{-3} \text {, }
$$$$
\mathrm{n}_{\mathrm{p} 4}=1,3 \cdot 10^{11} \mathrm{~cm}^{-3} \text {. }
$$

Table 1
\begin{tabular}{|c|c|c|c|c|c|c|}
\hline$\gamma_{\mathrm{b}}$ & $\mathrm{S}_{\mathrm{b}}$ & \multicolumn{4}{|c|}{$\eta(\%)$ for plasma densities: } \\
\cline { 3 - 7 } & $(\mathrm{MW})$ & $\mathrm{N}_{\mathrm{p}}=0$ & $\mathrm{n}_{\mathrm{p} 1}$ & $\mathrm{n}_{\mathrm{p} 2}$ & $\mathrm{n}_{\mathrm{p} 3}$ & $\mathrm{n}_{\mathrm{p} 4}$ \\
\hline 1,25 & 51,2 & 1,08 & 1,17 & 1,23 & 1,27 & 2,84 \\
\hline 1,4 & 82 & 1,69 & 1,74 & 1,79 & 1,81 & 2,44 \\
\hline 1,67 & 136,5 & 2,69 & 2,71 & 2,72 & 2,73 & 2,98 \\
\hline 2,29 & 265 & 2,55 & 2,62 & 2,60 & 2,63 & 2,75 \\
\hline
\end{tabular}

In Table 1 the values of $\eta$ for various densities of plasma and for various values of beam energy are presented. Let's note the following: first, $\eta$ increases with the growth of plasma density, and with $\gamma_{b}=1,25$ for $\mathrm{n}_{\mathrm{p} 4}=1,3 \cdot 10^{11} \mathrm{~cm}^{-3} \eta$ becomes more than two and a half times as much as the vacuum efficiency. Second, with growth of $\gamma_{b}$ for vacuum case and for all plasma cases except $\mathrm{n}_{\mathrm{p} 4} \eta$ grows, reaching the maximal value with $\gamma_{\mathrm{b}}=1,67$ and then decreases with $\gamma_{\mathrm{b}}=2,29$.

\section{Conclusions}

The dispersion equation, describing interaction of thin tubular electronic beam with plasma-filled coaxial waveguide which external surface is modulated by harmonic law, is received. It is shown that growth rates of instabilities are maximal for the modified backward cable mode of a corrugated coaxial line, and also that the plasma filling results in essential increasing of growth rate of instability in the frequency band $\omega<\omega_{p}$ and $\omega<\pi c / D$ at the backward cable mode, with this the frequencies of instability vary insignificantly. The nonlinear estimations of oscillations excitation efficiency by beam on backward cable mode are carried out. It is shown that the plasma filling results in significant efficiency growth.

\section{References}

1. Fainberg Ya.B., Gorbatenko M.F. // ZhTF (in russ.), 1959.-V.29, № 5.-P.549-562.

2. Berezin A.K., Buts V.A., Kovalchuk I.K. et al. // Preprint KhFTI 91-52 (in russ.).

3. Fainberg Ya.B., Bezjazychnyj I.A., Berezin A.K. et al. // Plasma Physics and Controlled Nuclear Fusion Research.-IAEA, Vienna, 1969.-V.2.-P.723-732.

4. Ostrovsky A.O., Ognivenko V.V. // R. \& E. (in russ.), 1979.-V.24, № 12.-P.2470-2477.

5. Carmel Y., Minami K., Kehs R.A. et al. // Phys. Rev. Lett., 1989.-v.62.-p.2389-2392.

6. Fainberg Ya.B., Bliokh Yu.P., Kornilov Ye.A. et al. // Dokl. AN UcrSSR. Ser. A. Fiz.-mat. \& techn. nauki (in russ.), 1990.-№11.-P.55-58.

7. Onishchenko I.N., Linetsky A.R., Matsiborko N.G. et al. // Pisma v ZhETF (in russ.), 1970.- V.12, № 8.-P.407-411. 